\section{PROGNOSTIC FACTORS FOR DURATION OF SICK LEAVE IN PATIENTS WITH CHRONIC LOW BACK PAIN, A SYSTEMATIC REVIEW}

${ }^{1}$ A A Steenstra, 'M P H Munhall, 'Invin, 'Van Eerd, ${ }^{2}$ Busse, ${ }^{3}$ Oranye, ${ }^{3}$ Passmore, ${ }^{1}$ HoggJohnson. 'Institute for Work and Health, Toronto, Canada; ${ }^{2}$ McMaster University, Hamilton, Canada; ${ }^{3}$ University of Manitoba, Winnepeg, Canada

\subsection{6/oemed-2013-101717.135}

Objectives If a worker hurts his/her back, many people want to know how long it will take before he/she returns to work (RTW). The worker wants to know because being off work can lead to insecurity and anxiety. The workplace wants to know whether it should make alternate work arrangements. Compensation agencies want to know, to guide intervention decisions for early and safe RTW. The objective of this review is to determine the factors that predict RTW from the sub-acute and chronic stage of a low back pain related episode of time away from work. The current review is an expansion of a review published in 2005 that examined the acute stage.

Methods A search of PubMed, EMBASE and PsycINFO from inception to February 2012 was conducted. Retrieved references will be screened for relevancy independently by two reviewers and when consensus cannot be reached a third reviewer will be consulted. Reviewers will not assess articles they are an author on. Quality appraisal and data extraction forms developed by the research team will be used. Analysis of the results will involve Levels of Evidence and, if possible, results will be pooled.

Results Of the 5027 references that were retrieved 117 relevant prognosis studies and 72 relevant intervention studies were found. Prognosis studies will be used to identify prognostic factors for RTW and intervention studies will be referred to in final reports as possible ways to address identified prognostic factors. The findings from this review will be used to create a handbook for clinicians involved in the RTW process and will be shared in four different workshops to various stakeholder groups.

Conclusions This review will provide insight into the factors that affect RTW among individuals at the sub-acute and chronic stages of time away from work due to low back pain.

\section{CHRONIC WIDESPREAD PAIN (CWP) AND JOB SATISFACTION AMONG THE THREE WHEELER TAXI (TUK TUK) DRIVERS IN HIKKADUWA, SRI LANKA}

P V De Silva. University of Ruhuna, Galle, Sri Lanka

10.1136/oemed-2013-101717.136

Objectives Three wheeler taxies are a very common mode of public transportation in Sri Lanka and other south Asian countries. These are three-wheeled vehicles with a cabin for drivers and passengers. In Sri Lanka these vehicles are commonly called "tuk-tuks". Working as a tuk tuk driver is an important source of employment for many Sri Lankan men. It has been reported that these drivers are commonly seeking medical care for chronic musculoskeletal pain. However this problem has not been studied systematically. Therefore, this research was carried out with the objective of study the CWP, other chronic joint pains and job satisfaction among the tuk tuk drivers in Hikkaduwa, Sri Lanka.

Methods This study was carried out among a sample of tuk tuk drivers, working in Hikkaduwa, Sri Lanka. Cluster sampling method was used to select the sample. A criterion given in the "Manchester Definition" for CWP was used for the identification of CWP. Data was collected using a self administered structured questionnaire.

Results Two hundred and twenty tuk tuk drivers were participated in the study. Mean age of drivers was 28.50 years with the range of 19 years to 77 years. Most $(81.8 \%)$ had an education up to grade 10. Mean duration of work as tuk tuk driver is 6.7 years. $29.5 \%$ of drivers were found to have CWP. Shoulder pain was the most prevalent $(22.7 \%)$ individual joint problem. Other reported problems include Back pain (20.0\%) neck pain (18.6\%), knee pain (15.9\%) and wrist pain (11.4\%). 47.7\% drivers were satisfied about their job. Significantly higher proportion of drivers with CWP were unsatisfied about their job compared to drivers without CWP ( $\mathrm{P}<0.05)$.

Conclusion Almost 30\% of tuk tuk drivers were found to have CWP. And drivers with CWP are less likely to be satisfied with their job.

\section{CLINICAL AND OCCUPATIONAL PROFILE OF PROFESSIONAL DRIVERS FROM A SAMPLE IN SĆO PAULO, BRAZIL}

E C S Sá, Rachkorsky, Lessa, Gimenes, Zerbini, Leyton. Faculdade de Medicina da Universidade de Sāo Paulo, Sāo Paulo, Brazil

\subsection{6/oemed-2013-101717.137}

Objectives To identify the clinical and occupational profile of professional drivers, with emphasis on visual acuity, who participated in the "Comandos de Saúde" program performed at São Paulo, Brazil, from 2009 to 2011.

Methods We conducted a retrospective cross-sectional analysis using data collected from a sample of 787 drivers in eight different dates, from 2009 to 2011, from 'Comandos de Saúde' program of the Medicine School from São Paulo University.

Results $99.8 \%$ of the drivers were men, $53.6 \%$ had the age between 18 and 45 years. Regarding education $58.1 \%$ have not finished high school and $2 \%$ had a college degree. In assessing visual acuity, $10.4 \%$ of drivers were unable under the minimum criteria established by law and $2.1 \%$ had abnormal vision for colours.

Discussion The social profile and the findings related to visual acuity did not differ from the findings in other similar studies. It is known that visual acuity is one of the most important factors to driving safely, being an important issue to be addressed in occupational health evaluations from this workers.

Conclusions It is very important to the occupational health professionals regularly assess the health of professional drivers, with emphasis on visual acuity, which is the most important factor for their safety.

\section{COMPUTER VISION SYNDROME (CVS) IN ADMINISTRATIVE PROFESSIONALS AND THE EVALUATION OF ERGONOMIC CONDITIONS OF THE WORKPLACE}

${ }^{1}$ E C S Sá, ${ }^{2}$ Silva-Junior, ${ }^{2}$ Leite, ${ }^{2}$ Morrone. ${ }^{1}$ Faculdade de Medicina da Universidade de Sāo Paulo, Sāo Paulo, Brazil; ' Faculdade de Ciências Médicas da Santa Casa de Sāo Paulo, Sāo Paulo, Brazil

\subsection{6/oemed-2013-101717.138}

Introduction Computer vision syndrome (CVS) is the combination of vision and eye problems associated with the use of computers. The CVS may have a significant impact on visual 